\title{
SECOND REGULARIZED TRACE OF A DIFFERENTIAL OPERATOR WITH SECOND ORDER UNBOUNDED OPERATOR COEFFICIENT GIVEN IN A FINITE INTERVAL
}

\author{
ÖZlem BaKşi, Serpil Karayel And Yonca Sezer
}

Abstract. In this work, we establish a formula for the second regularized trace of a second order differential operator with unbounded operator coefficient given in a finite interval.

Mathematics subject classification (2010): 47A10, 34L20, 34B05, 34B09.

Keywords and phrases: Hilbert space, kernel operator, regularized trace, resolvent, spectrum.

\section{REFERENCES}

[1] I. C. Gohberg AND M. G. KREIN, Introduction to the Theory of Linear Non-self Adjoint Operators in Hilbert Space, Translation of Mathematical Monographs (1969), vol. 18.

[2] V. I. GoRBACHUK, On the asymptotic behaviour of the eigenvalues of boundary value problems for differential equations in a space of vector-valued functions, Ukr. Matem. J. 27 (1975), no. 5, 657-664.

[3] I. M. Gelfand AND B. M. Levitan, On a formula for eigenvalues of a differential operator of second order, Dokl. Akad. Nauk SSSR, T. 88 (1953), no. 4, 593-596 (in Russian).

[4] L. A. DikiY, On a formula of Gelfand-Levitan, Usp. Mat. Nauk 8 (1953), no. 2, 119-123 (in Russian).

[5] C. J. Halberg And V. A. KRAmer, A generalization of the trace concept, Duke Math. J. 27 (1960), no. 4, 607-618.

[6] B. M. Levitan, Calculation of the regularized trace of Sturm Liouville Operator, Usp. Mat. Nauk 19 (1964), 161-164 (in Russian).

[7] B. M. Levitan And I. S. SARgsyan, Sturm-Liouville and Dirac Operators, Kluwer, Dordrecht (1991).

[8] T. C. Fulton And S. A. Pruess, Eigenvalue and eigenfunction asymptotics for regular SturmLiouville problems, J. Math. Anal. Appl. 188 (1994), 297-340.

[9] E. E. AdIGÜZELOV, About the trace of the difference of two Sturm-Liouville operators with operator coefficient, Iz. AN AZ SSR, seriya Fiz-Tekn. i Mat. Nauk 5 (1976), 20-24 (in Russian).

[10] R. Z. Chalilova, On regularization of the trace of the Sturm-Liouville operator equation, Funks. analiz, teoriya funksiy i ik pril. - Mahachkala 3 (1976), 154-161 (in Russian).

[11] F. G. Maksudov, M. Bayramoglu and E. E. AdigÜZelov, On regularized traces of SturmLiouville operator on a finite interval with unbounded operator coefficient, Dokl. Akad, Nauk SSSR, English translation, Soviet Math, Dokl 30 (1984), no. 1, 169-173.

[12] E. E. AdigÜZElov, H. Avci AND E. GÜL, The trace formula for Sturm-Liouville operator with operator coefficient, J. Math. Phsy. vol. 42 (2001), no. 6, 1611-1624.

[13] E. E. AdIGÜZELOV AND Ö. BAKşI, On the regularized trace of the differential operator equation given in a finite interval, Sigma Journal of Engi. and Natural Sciences 2004/1, 47-55.

[14] E. GÜL, The trace formula for a differential operator of fourth order with bounded operator coefficients and two terms, Turk. J. Math., TÜBITAK 28 (2004), 231-254.

[15] N. M. As lanova, A trace formula of a boundary value problem for operator Sturm-Liouville equation, Sib. Math. J. 49 (2008), no. 6, 959-967.

[16] M. Bairamogly, N. M. Aslanova, Distribution of eigenvalues and trace formula for the SturmLiouville operator equation, Ukr. Math. J. 62 (2010), no. 7, 1005-1007. 
[17] F. Gesztesy, R. Weikard, M. Zinchenko, On spectral theory for Schrödinger operators with operator-valued potentials, Journal of Differential Equations 255 (2013), no. 7, 1784-1827. 